\title{
As comunidades de Manguinhos na história das favelas no Rio de Janeiro
}

\author{
Tania Maria Fernandes[1], Renato Gama-Rosa Costa[2]
}

\begin{abstract}
Resumo
Este artigo buscou discutir a trajetória das comunidades de Manguinhos, no universo das favelas da cidade do Rio de Janeiro, no que diz respeito às políticas de habitação e urbanização e aos processos de ocupação. A história centenária dessa região reflete a disputa pelo espaço urbano e a complexidade do tema das favelas, frente aos problemas historicamente vinculados a tal tipo de moradia, comunidade e localidade.
\end{abstract}

Palavras-chave: história; favelas; Manguinhos; Rio de Janeiro.

\section{Las comunidades de Manguinhos en la historia de las favelas en Río de Janeiro}

\section{Resumen}

Este artículo buscó discutir la trayectoria de las comunidades de Manguinhos, en el universo de las favelas de la ciudad de Río de Janeiro, respecto a las políticas de habitación y urbanización y los procesos de ocupación. La historia centenaria de esa región refleja la disputa por el espacio urbano y la complejidad del tema de las favelas, frente a los problemas históricamente vinculados a este tipo de vivienda, comunidad, y localidad.

Palabras clave: historia; favelas; Manguinhos; Río de Janeiro.

\section{The Manguinhos communities in the history offavelas in Rio de Janeiro}

\section{Abstract}

This article aimed at discussing the trajectory of Manguinhos communities, in the context of favelas in the city of Rio de Janeiro, mainly linked to housing and urban policies and occupation proceedings. The centennial history of this region reflects urban space disputes and the complexity of favelas theme upon historically problems linked to this kind of housing, community, and locality.

Keywords: history; favelas; Manguinhos; Rio de Janeiro.

\section{Les communautés de Manguinhos dans l'histoire des bidonvilles à Rio de Janeiro}

\section{Résumé}

Cet article traite de l'histoire des communautés de Manguinhos (RJ), dans le monde des bidonvilles (favelas) de cette ville, non seulement en ce qui concerne les politiques d'habitation et d'urbanisation, mais aussi les process de occupation. L'histoire centenaire de cette région reflète la lutte pour l'espace urbain et la complexité de la question des bidonvilles, face aux problèmes historiquement associés à ce type de logement, de communauté et d'emplacement.

Mots-clés: histoire; bidonvilles (favelas); Manguinhos; Rio de Janeiro. 
$\mathrm{E}$ ste texto foi realizado no âmbito de uma pesquisa interinstitucional mais ampla de abordagem histórica acerca do morar em Manguinhos, Rio de Janeiro, uma área de habitação popular. O mesmo tomou como foco questões que envolvem as principais políticas de habitação e urbanização, a origem dos moradores e os processos de ocupação da área, ao longo do século XX, com ênfase no pós-década de 1950.

A equipe da presente investigação foi composta por pesquisadores da Fundação Oswaldo Cruz (Fiocruz), técnicos de pesquisa moradores das comunidades e alunos das escolas da área que atuam na Fiocruz. Esta assumiu como um de seus pontos norteadores a credibilidade que histórias e memórias compartilhadas entre moradores e investigadores podem contribuir para a redução das desigualdades e à promoção dos direitos básicos civis e políticos dessas populações, por meio de ações e debates nos campos interdisciplinares envolvendo a saúde pública. Talvez seja difícil detectar nestas poucas páginas o processo vivenciado por esses atores e o aprendizado mútuo que tal relação propiciou, transformando todos aqueles envolvidos na pesquisa em parceiros de uma história em construção em torno de um conhecimento compartilhado.

A área de Manguinhos, onde situam-se as comunidades deste estudo, está localizada na zona Norte do Rio de Janeiro, às margens da Baía de Guanabara, ocupada ao longo do século XX por moradias populares que se instalaram devido a ações individuais e em grupos, ou por meio de políticas públicas habitacionais com um quadro que contrapõe abandono dos governantes e luta dos moradores. A própria denominação aponta para uma de suas descrições como área de manguezal que, no entanto, atualmente pouco mostra desta característica em função do intenso aterramento ao longo do século por lixo proveniente da cidade ou material de grandes obras de urbanização.

Trata-se de um conjunto de comunidades com especificidades internas bastante singulares que conjugam origens, trajetórias e perfis diferenciados e construções sociais formatadas historicamente, em relação estreita com os determinantes políticos, econômicos e sociais, os quais construíram as grandes cidades brasileiras ao longo do século XX.

A incorporação do termo 'comunidade' em substituição à 'favela', sendo referência socioespacial, foi tratado como uma decisão coletiva entre a equipe, à medida que está presente no cotidiano de Manguinhos e explicitado nas narrativas dos entrevistados, com apreciação de diferentes significados às variadas terminologias indicadas para tais agrupamentos sociais.

As denominações que buscam substituir a terminologia 'favela' como 'comunidade', 'complexo' e classificações como 'grupamentos' ou 'aglomerados subnormais' e também 'bairro' tentam, na realidade, criar novas conotações para o termo, pouco contribuindo para mudanças significativas. 'Comunidade' passou a ser empregada no interior de movimentos sociais na expectativa de rompimento com o preconceito em relação tanto à provisoriedade, quanto à violência e marginalidade que lhe são apregoadas. Está também associada à atuação de órgãos de ação comunitária e a alguns campos das ciências sociais, que explicitam um modo de cooperação em comum, termo que, para Lúcia Ozório, "afirma a 
comunidade na favela, intensificando sentidos ligados a processos de liberdade e compartilhamento". ${ }^{1}$ Apesar da perspectiva de substituição, as nomenclaturas favela e comunidade permanecem utilizadas, como ressalta Linda Gondim, "como atributo de uma identidade social e grupal". Como foi possível perceber na atuação junto aos moradores, participantes do projeto ou não, os dois também estão associados ao contexto e ao uso ao qual estão relacionados, em processos reivindicatórios, marcas de pertencimento ou explicitação de mudanças, atuando conforme um jogo de interesses e sentidos.

A palavra 'complexo' significa um agrupamento de favelas e foi inicialmente aplicada por órgãos policiais, mas também é utilizada no Programa de Aceleração de Crescimento (PAC/Manguinhos), apesar de não ser empregada pelos moradores em geral, ao menos em Manguinhos.

A denominação 'subnormal' foi incorporada pelo Instituto Brasileiro de Geografia e Estatística (IBGE) para definir áreas "dispostas, de forma desordenada e densa, e carentes, em sua maioria, de serviços públicos essenciais" (2003) ${ }^{3}$ e vem reiterar a distinção entre áreas com definições de normalidade e, consequentemente, anormalidade, reafirmando-as como zonas de exclusão.

'Comunidade’ passou a ser empregada no
interior de movimentos sociais na expectativa
de rompimento com o preconceito em relação à
violência e marginalidade que lhe são apregoadas

'Comunidade urbanizada' ou 'bairro' também têm sido utilizados no Rio de Janeiro, recentemente como justificativa governamental de minimizar a distância entre os espaços da cidade. Porém, configura-se uma estratégia para diminuir o número das favelas e consequentemente tentar arrefecer o "problema", o que provocou o posicionamento de várias instâncias públicas e privadas e de moradores. O papel do Estado e a distribuição dos serviços públicos nos diferentes espaços da cidade são questões que polarizam essas opiniões e retratam a diferença dos olhares para as populações. ${ }^{4}$

Os personagens, partícipes desta história urbana contemporânea, foram relevantes para tais estudos, e as entrevistas elaboradas com moradores de Manguinhos possibilitaram perceber a identificação desses atores com

\footnotetext{
'Lúcia Ozório, Perspectivas da pesquisa comunitária: comunidade como práxis e seus diálogos com as histórias orais de vida, 2006. Disponível em: <http://www.revispsi.uerj.br/v7n1/artigos/html/v7n1aO4.htm>, acesso em: 28 de fevereiro de 2012.

${ }^{2}$ Linda Maria de Pontes Gondim, Habitação Popular. Favela e Meio Ambiente. I Encontro Nacional da Associação Nacional de Pesquisa e Pós-Graduação em Arquitetura e Urbanismo, 2010, Rio de Janeiro. I ENANPARQ - Arquitetura, cidade, paisagem e território: percursos e prospectivas. Rio de Janeiro, PROURB, 2010, vol. 1, p. 12

${ }^{3}$ Censo Demográfico 2010. Aglomerados subnormais. Primeiros resultados. Instituto Brasileiro de Geografia e Estatística - IBGE. Ministério do Planejamento, Orçamento e Gestão. Disponível em: <http://biblioteca.ibge.gov. br/visualizacao/periodicos/92/cd_2010_aglomerados_subnormais.pdf>, acesso em 28 de fevereiro de 2012. ${ }^{4}$ Duilo Victor; Rogério Daflon; Waleska Borges, "Novo rótulo para a velha miséria”, O Globo, Rio de Janeiro, 31 de maio de 2011; Rogério Daflon, Selma Schmidt, "O caminho para se chegar à cidade formal", O Globo, Rio de Janeiro, 5 de junho de 2011
} 
seu espaço e sua história, nas diversas versões que surgiram sobre os vários processos de ocupação e relações com as comunidades. A metodologia de História Oral, neste sentido, assumiu lugar de destaque ao lado de outras fontes (relatórios, programas e projetos, legislação e imprensa), iluminada pela vasta bibliografia acerca do urbano e das favelas no Brasil. Os depoimentos, neste conjunto, configuram-se um trabalho coletivo, no qual a narrativa é percebida como um processo de construção social baseado na memória com os fatores que a envolvem e compõe um conjunto de versões, que se torna rico quando observado como tal.

Os moradores que não foram em sua totalidade incluídos neste texto, mas que compõem os presentes estudos, foram selecionados nos contatos e nas visitas às comunidades, com o auxílio daqueles que atuam no projeto e congregam moradores e lideranças vinculadas às associações de moradores, idosos ou não. Foram entrevistados, também, alguns técnicos da Prefeitura com trajetórias vinculadas a projetos de urbanização e habitação voltados para favelas.

\section{As cidades e a urbanização no Brasil: e os pobres onde ficam?}

O adensamento populacional das grandes cidades brasileiras, principalmente após a década de 1950, como consequência da ampliação da atividade econômica industrial no espaço urbano em contraponto à instabilidade agrária, decorrente das secas e do sistema latifundiário, ocorreu sem haver uma correlação de igualdade entre emprego, moradia e estrutura urbana, conforme está apontado na ampla bibliografia sobre o tema. Foram criadas cidades industriais que, como assinalou Lefebvre, ${ }^{5}$ estão associadas ao crescimento do capital comercial, dos capitalistas, dos mercados e da mão de obra de baixo custo - os pobres, que, no Brasil, com a grande migração, acabaram concentrados nas regiões Sul e Sudeste.

A valorização do solo urbano induziu ao crescimento e à mudança das características, não somente do espaço como também da própria sociedade. As políticas econômica e social brasileiras e a carência de planejamentos urbano e habitacional, além da organização da própria sociedade, contribuíram para estimular os processos de ocupação, caracterizados tipologicamente como favelas, em espaços diferenciados, colocados à margem da cidade como zonas de exclusão, marcados pela desigualdade social, mesmo que intrínsecos ao espaço físico da cidade.

A proximidade das habitações, as soluções conjuntas para os problemas de infraestrutura, a sociabilidade, a relação com a pobreza e a provisoriedade e o enfrentamento de reações de caráter preconceituoso, caracterizam, de forma superficial, esta tipologia construída historicamente sobre o pressuposto de que a favela configura-se como um espaço regido por normas e regras diferenciadas da ocupação territorial urbana. De fato, tais lugares apresentam significados, regras e códigos próprios, embora, como ressalta Carlos Nelson

${ }^{5}$ Henri Lefebvre, A revolução urbana, Belo Horizonte, Universidade Federal de Minas Gerais, 1999. 
Ferreira dos Santos, estejam "mergulhados e embebidos na cultura, economia e sociedade urbana que lhe fazem parte", ${ }^{6}$ compondo toda a cidade.

A constituição de 1988, como resposta de um processo político de retomada da democracia, incluiu propostas de fortalecimento do poder local, orientadas por preceitos de gestão urbana contemporânea, presentes nas indicações governamentais, nas posturas internacionais em torno da globalização, nas novas formas de gestão, na participação popular e na explicitação e no envolvimento nos projetos locais, como assinalado por Bonduki. ${ }^{7}$ Entre 1985 e 2006, seguindo essas orientações constitucionais para a organização do espaço urbano, observou-se a criação de bairros e regiões administrativas, que passaram a englobar as áreas consideradas das favelas, como uma medida oficialmente justificada para o gerenciamento do espaço físico e da estruturação dos serviços locais. ${ }^{8}$

A história do Rio de Janeiro é exemplar no que tange à configuração das favelas em um processo secular que abarcou etapas distintas marcadas, no entanto, pelo segregacionismo em relação às populações de baixo poder aquisitivo. Grandes obras nas áreas do centro da cidade em associação às questões econômicas e de saúde pública com destruição das casas populares, nos primeiros anos do século XX, além da modernização das

A história do Rio de Janeiro é exemplar no que
tange à configuração das favelas em um processo
secular [...] pelo segregacionismo em relação às
populações de baixo poder aquisitivo

moradias nas décadas seguintes, ocasionaram deslocamento populacional e ocupação de encostas e de outras áreas por uma grande parcela da população excluída das melhorias habitacionais e econômicas. A política econômica e a industrialização implementada na década de 1950 promoveram também profunda migração de população pauperizada e ampliaram as favelas fadadas ao descaso do Estado e ao preconceito de uma sociedade urbana cada vez mais excludente.

Como solução para o que era compreendido como 'problema' de âmbito social, político e jurídico, verificou-se a formulação de diversas políticas públicas, as quais intercalavam propostas de socialização, integração e, principalmente, erradicação em resposta aos interesses estabelecidos entre Estado

\footnotetext{
${ }^{6}$ Carlos Nelson Ferreira dos Santos, "Como projetar de baixo para cima: uma experiência em favela”, Revista de Administração Municipal, n. 156, ano 26, Rio de Janeiro, IBAM, 1980, p.7-27 apud Maria Laís Pereira da Silva, "Sobre as favelas e seus moradores: palavras de Carlos Nelson Ferreira dos Santos", Revista da Faculdade de Arquitetura e Urbanismo da Universidade Federal do Rio de Janeiro, n. 1, 2008, p. 11. Nesse texto, Maria Laís traçou uma análise sobre várias obras de Carlos Nelson.

${ }^{7}$ Nabil Bonduki, "Habitat e Qualidade de Vida: as práticas bem sucedidas em cidades brasileiras", In: . (org), Habitat: Práticas Bem Sucedidas em habitação, meio ambiente e gestão urbana nas cidades brasileiras, São Paulo, Studio Nobel, 1996.

${ }^{8}$ Adriano Alem, Breve relato sobre a formação das Divisões Administrativas na Cidade do Rio de Janeiro período de 1961 a 2007, Prefeitura da Cidade do Rio de Janeiro, Secretaria Municipal de Urbanismo, Instituto Pereira Passos, 2008.
} 
e classe dominante diante da valorização de determinadas áreas da cidade e de ações de âmbito eleitoreiro. ${ }^{9}$

Até a década de 1980 a favela carioca manteve-se fora do círculo formal de moradia, conforme analisado, entre outros estudiosos, por Maria Lais Pereira da Silva, Guida Nunes, Lícia Valladares e Rafael Soares Gonçalves, ${ }^{10}$ como uma mancha branca nos mapas da cidade, embora movimentos sociais reivindicassem uma nova ação estatal, o que se verificou com as discussões e conquistas em torno da Constituição de 1988. A formalização destes novos bairros e a incorporação das favelas não as alterou substancialmente, na medida em que se pautava no direcionamento de opções habitacionais e urbanísticas precárias, serviços públicos desiguais em relação ao restante da cidade e manutenção da divisão social do trabalho de forma excludente.

As associações de moradores de favelas apresentam, neste cenário, papéis diferenciados em conjunturas distintas. Criadas no início da década de 1960, vinculadas aos movimentos populares, as mesmas configuravam o panorama político daquele momento contra as remoções e a ditadura militar articuladas, em vários casos, ao Partido Comunista Brasileiro. Buscavam solucionar, também, problemas coletivos de responsabilidade do Estado relacionados a serviços básicos que faltavam ou eram oferecidos às favelas de forma precária, como energia elétrica, água, saneamento e distribuição de correspondências.

Ainda nessa década com o movimento ditatorial, a atuação dessas instituições se viu atrelada aos poderes públicos, por meio principalmente da Secretaria de Serviço Social, que, com aporte legislativo, ${ }^{11}$ estabeleceu controle tanto das favelas, no que tange às construções, ao comércio, à distribuição de luz, como de seus moradores, com a exigência do cadastramento individual. Com o processo de abertura política, ao final de 1970, e a mobilização comunitária, novas associações de moradores de favelas foram criadas e retomaram a discussão dos direitos à cidadania, deparando-se, ao mesmo tempo, com outras formas de organização articuladas, em muitos casos, ao tráfico de drogas, possuindo pouca semelhança com as que lhes deram origem. A criminalidade e a violência impostas pelo tráfico, a estes espaços, mudaram o foco de interesses, destruíram o contrato social vigente e estabeleceram regras específicas com outra lógica, atreladas ao medo e à opressão. A maioria das negociações e reivindicações passou a ser intermediada por tais grupos num processo de criminalização da pobreza e de esvaziamento do caráter politizador das classes populares.

Outras lideranças e ações comunitárias se deslocaram para movimentos específicos relacionados às várias formas de expressão cultural como o hip-hop, os grafites, à procura de uma reflexão e atuação na perspectiva de atrair jovens

\footnotetext{
${ }^{9}$ Andrelino Campos, Do quilombo a favela: a produção do espaço criminalizado, Rio de Janeiro, Bertrand, 2005; Marcelo Baumann Burgos, "Dos parques proletários ao Favela-Bairro", In: Marcos Alvito, Alba Zaluar (org), Um século de favela, Rio de Janeiro, Fundação Getúlio Vargas, 2006; Marcos Alvito, As cores de Acari: uma favela carioca, Rio de Janeiro, Fundação Getulio Vargas, 2001.

${ }^{10}$ Maria Laís Pereira Silva, Favelas cariocas (1930-1964), Rio de Janeiro, Contraponto, 2005; Guida Nunes, Rio: metrópole de favelas, Petrópolis, Vozes, 1976; Lícia do Prado Valladares, "A invenção da Favela: do mito de origem a favela.com". Rio de Janeiro: Editora FGV, 2005; Rafael Soares Gonçalves, "A Política, o Direito e as favelas do Rio de Janeiro: um breve olhar histórico", Urbana Revista eletrônica do Centro Interdisciplinar de Estudos da Cidade, Universidade Estadual de Campinas, vol. 1, 2006. Para consulta a esse texto e outros de números anteriores, acessar: <http://www.ifch.unicamp.br/ciec/revista/>.

"Os Decretos 870, de 1967, e 3.330, de 1969, determinavam as diretrizes de funcionamento e as relações das Associações de Moradores com o Estado, atrelando-as aos poderes públicos como extensão destes para as favelas.
} 
e retirá-los do crime e do tráfico. Tomaram corpo também alguns fóruns que apontam para debates e ações sobre o Estado democrático de direitos, por meio da criação dos conselhos gestores e da realização de conferências distritais temáticas, acenando para novas formas de enfrentamento e organização popular.

As mudanças verificadas no espaço urbano brasileiro nos últimos cem anos alteraram substancialmente as cidades. Na grande maioria, porém, ignoraram a identidade do morador das favelas com seu 'lugar', promovendo remoções e construções inadequadas aos perfis familiar e social, como no caso de Manguinhos.

No início do século XXI, a implantação do Programa de Aceleração do Crescimento e a realização dos jogos olímpicos ressaltaram, na pauta da política brasileira, a existência de favelas com discussões e debates sobre a contemporaneidade do espaço urbano, causando um impacto também sobre Manguinhos.

\section{Manguinhos nos contextos históricos \\ dos projetos urbanos: do barraco aos prédios}

A ocupação de Manguinhos, ocorrida pelo século XX, é associada a aspectos socioeconômicos gerais, às mudanças socioespaciais, às políticas públicas e à densa ocupação, além das obras nas áreas marginais à Baía de Guanabara, as quais mudaram sua configuração original - aterrando suas enseadas, praias, pequenas ilhas, rios e manguezais. ${ }^{12}$ Um belo cenário de margem de baía foi destruído por material insalubre como lixo e terra de demolições, e então transformado em lugar de moradia "para um determinado tipo de pessoas: 0 favelado", como ressalta a moradora Gleide Guimarães. ${ }^{13}$

A ocupação secular desta área formou um conjunto bastante diversificado de habitações com características do que se descreve, em geral, como favelas, sem legalização e fora dos padrões formais estabelecidos de moradia e com serviços públicos ausentes ou precários, com um total de aproximadamente 60.000 habitantes, em 2010. Caracteriza-se como uma região com sérios problemas ambientais, com poluição do ar, dos rios e do solo, devido ao lançamento de dejetos in natura, tanto das fábricas como das moradias, nos rios que cortam a região, além da proximidade com a Avenida Brasil e a Refinaria de Petróleos de Manguinhos S.A., conforme pode ser observado na Figura 1.

Entre as décadas de 1920 e 1940, diversas propostas de urbanização, incluindo o Plano de Melhoramentos formulado por Donat-Alfred Agache, ${ }^{14}$ foram apresentadas para a área, que ainda se encontrava com poucas casas, indicando-a como estratégica para o crescimento industrial e habitacional devido a sua proximidade do centro da cidade e da região portuária, fato que contribuiria para a instalação em Manguinhos de uma zona industrial. Outro projeto, proposto para a região, previa a criação de um park-way ao longo do Rio FariaTimbó, na perspectiva de transformar Manguinhos em um dos "mais atraen-

\footnotetext{
12EImo Amadro, Entrevista concedida ao projeto História e Memória de Manguinhos desenvolvido pela Casa de Oswaldo Cruz/ Fiocruz, Acervo DAD/COC, 08 de setembro de 2005; Alexandre Pessoa, "Manguinhos como pôde ser, ou: pequena história esquecida do subúrbio carioca", Revista da Faculdade de Arquitetura e Urbanismo da Universidade Federal do Rio de Janeiro, n. 2, 2010.

${ }^{13}$ Gleide Guimarães, Manguinhos: histórias de pessoas e lugares, Vídeo documentário, Fiocruz/ LTM e COC, 2009. Disponível em: <http://www.conhecendoManguinhos.fiocruz.br/?q=node/130>.

${ }^{14}$ Alfred Hubert Donat Agache, Cidade do Rio de Janeiro: remodelação, extensão e embelezamento, Plano Agache, Rio de Janeiro, Foyer Brésilien, 1930.
} 


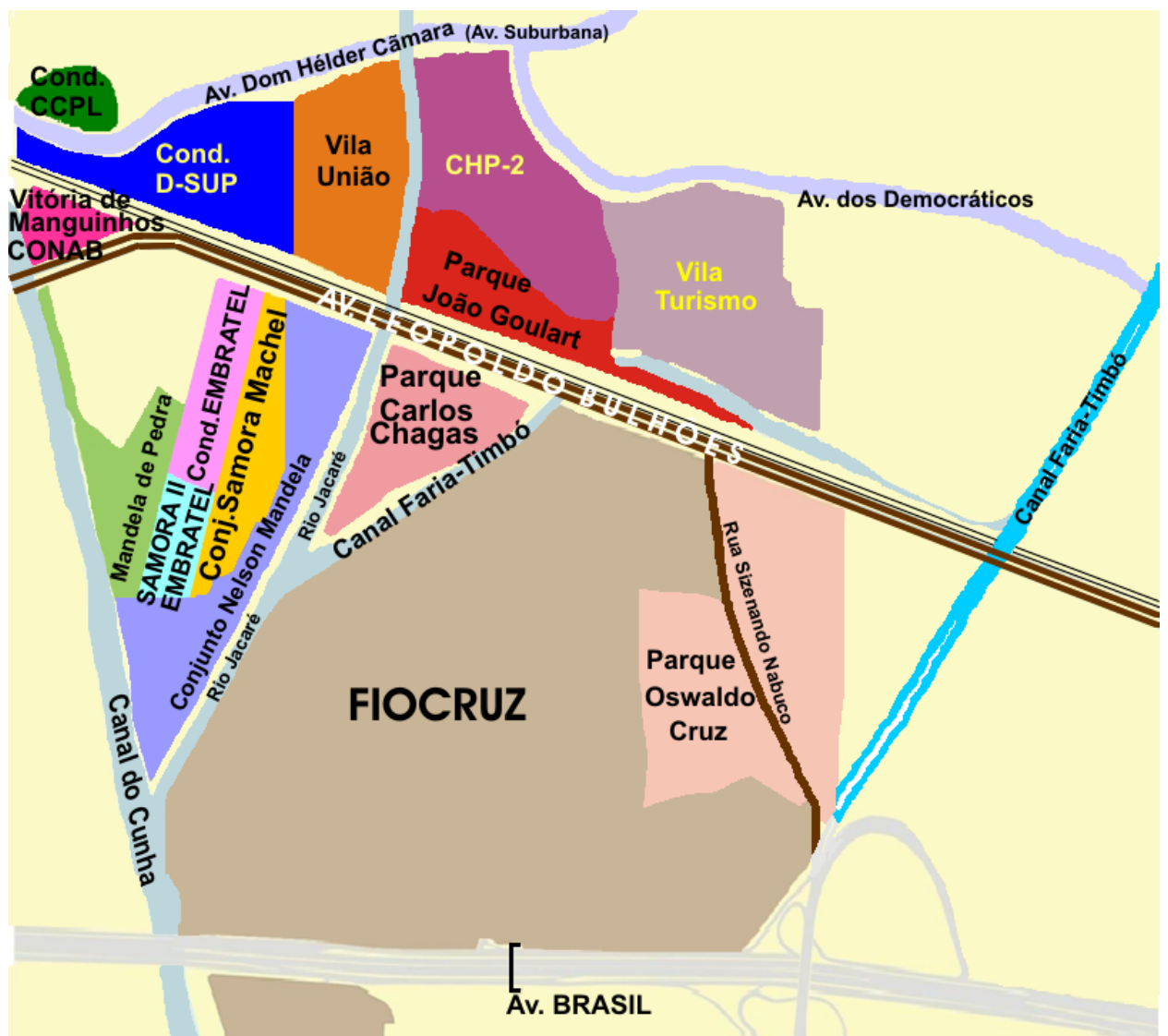

Figura 1. Desenho ilustrativo da distribuição das Comunidades do Complexo de Manguinhos em 2013.

tes subúrbios cariocas".15 Durante a gestão do Prefeito Henrique Dodsworth (1937-1945), elaborou-se o 'Plano da Cidade do Rio de Janeiro', que incorporava a proposta do park-way Faria-Timbó e o Plano Agache (1927-1930), e mais uma vez propunha a transformação de Manguinhos em um bairro industrial urbanizado. Esses projetos limitaram-se, apenas, ao aterramento, à retificação de rios e à construção de alguns conjuntos habitacionais. ${ }^{16}$

Até a década de 1970, ao lado da ocupação por moradias, ocorreu em Manguinhos a implantação de várias indústrias e empresas públicas ou privadas, como o Instituto Oswaldo Cruz - IOC (atual Fundação Oswaldo Cruz), a Empresa de Correios e Telégrafos (ECT), a Empresa Brasileira de Telecomunicação (Embratel), a Companhia Nacional de Abastecimento (Conab), a Refinaria de Petróleos de Manguinhos S. A. e a fábrica de cigarros Souza Cruz.

Esse processo, no entanto, não foi consubstanciado a um programa governamental para constituição de um bairro industrial, como previsto nos projetos propostos desde a década de 1920, mas aos fatores econômicos, à baixa valorização da área e à proximidade com o centro da cidade. A disponibilidade

15José de Oliveira Reis, "Notícia sobre o Park-Way Faria-Timbó", Revista Municipal de Engenharia, vol. 10, n. 2 , 1943, 94 p

${ }^{16}$ As propostas de projetos de intervenção para Manguinhos entre as décadas de 1920 e 1940 não se constituíram em análise deste texto, mas podem ser observadas na publicação de Tania Maria Fernandes e Renato Gama-Rosa Costa, Tania Maria Fernandes e Renato Gama-Rosa Costa. História de Pessoas e Lugares: memórias das comunidades de Manguinhos. Rio de Janeiro: Ed. Fiocruz, 2010. 
de espaços livres, a oferta de emprego e de mão de obra de baixo custo foram fatores que se associaram, tanto para o adensamento populacional, como para a implantação das empresas.

O IOC, atual Fundação Oswaldo Cruz, mais antiga instituição pública da área, teve parte de seus terrenos ocupados por construção de moradias, sem autorização legal, reafirmando a relação entre habitação e trabalho na medida em que incorporava a mão de obra existente e atraia novos trabalhadores/moradores. Esse processo gerou negociações que envolveram os residentes e o poder público, em várias instâncias e diferentes conjunturas. ${ }^{17} \mathrm{Um}$ acordo firmado, em 1922, entre o instituto, o Ministério de Viação e Obras Públicas e a Empresa de Melhoramentos da Baixada Fluminense, apresentava como objetivo "transformar os pântanos e áreas alagadas em terrenos secos, salubres e irrigáveis". ${ }^{18}$ Tais intervenções como outras, no entanto, não converteram a área de Manguinhos em "terrenos secos, salubres e irrigáveis", mas sim em úmidos e altamente vulneráveis que acolheram um enorme contingente populacional, em geral migrado, que não encontrou lugar melhor para se instalar em outras áreas da cidade.

Ao longo das décadas de 1940 e 1950, em uma política controladora e populista, diversos órgãos, como o Departamento de Construções Proletárias (DCP), o Departamento de Habitação Popular (1946), a Fundação Leão XIII (1947), a Cruzada São Sebastião (1955) e o Serviço Especial de Recuperação das Favelas e Habitações Anti-Higiênicas - SERFHA (1956), implementaram políticas sociais e ações específicas nas favelas do Rio de Janeiro. ${ }^{19} \mathrm{~A}$ Fundação Leão XIII ${ }^{20}$, criada pela Igreja Católica diante da preocupação com as possíveis ações políticas de grupos comunistas frente aos moradores de favelas, teve uma atuação destacada nessas comunidades, nas quais pregava o assistencialismo; atuava no cadastramento de moradores para realocação, controle e manutenção dos conjuntos de habitações; buscava viabilizar alguns serviços básicos como abastecimento de água, rede de esgoto, iluminação elétrica e rede viária e, sobretudo, controlava a expansão das comunidades. ${ }^{21}$

Na década de 1950, como ocorreu em outras áreas do Rio de Janeiro, foram construídas habitações populares destinadas a grupos específicos como o Conjunto Manguinhos, instalado como Centro de Habitação Provisória, e o Parque São José, financiado pela Fundação das Pioneiras Sociais, destinado

\footnotetext{
${ }^{17}$ A posse do terreno do Instituto Oswaldo Cruz somente foi alcançada em 1948, quando foi lavrado o Termo de Entrega ao Instituto Oswaldo Cruz de dois terrenos, demarcando e oficializando sua área em Manguinhos. ${ }^{18}$ Brazil Ferro-Carril, Rio de Janeiro, XIII: 271, 1922; Termo de ajuste entre o Instituto Oswaldo Cruz e a Empresa de Melhoramentos da Baixada Fluminense. DAD/FIOCRUZ, Fundo do Instituo Oswaldo Cruz, seção de Administração, série Administração Geral, 25/02/1922. Benedito Tadeu Oliveira, Renato Gama-Rosa Costa, Alexandre Pessoa, Um Lugar para a Ciência. A formação do campus de Manguinhos, Rio de Janeiro, Fiocruz, 2003; Alexandre Pessoa, "Manguinhos como pôde ser, ou: pequena história esquecida do subúrbio carioca", Revista da Faculdade de Arquitetura e Urbanismo da Universidade Federal do Rio de Janeiro, n. 2, 2010; Tania Maria Fernandes; Renato Gama-Rosa Costa, História de Pessoas e Lugares: memórias das comunidades de Manguinhos, Rio de Janeiro, Fiocruz, 2010.

19 Vitor Vincent Valla, “Educação, participação, urbanização: uma contribuição à análise histórica das propostas institucionais para as favelas do Rio de Janeiro, 1941-1980", Cadernos de Saúde Pública, Rio de Janeiro, vol. 1, n. 3, 1985, p. 282-296. Flávia Brito, "Entre a estética e o hábito: o Departamento de Habitação Popular do Rio de Janeiro (1946-1960)", In: Anais do VIII Seminário da História da Cidade e do Urbanismo. Niterói, novembro de 2004; Para consulta a esse texto e aos demais textos do seminário, acessar: <http://web3.ufes.br/xishcu/cdanais/anais-schu2O10.html; Marcelo Baumann Burgos, "Dos parques proletários ao Favela-Bairro", In: Marcos Alvito, Alba Zaluar (org), Um século de favela, Rio de Janeiro, Fundação Getúlio Vargas, 2006.

2oUma das ações definida para a Fundação Leão XIII era a "assistência material e moral aos habitantes dos morros e favelas do Rio de Janeiro”. Estatutos da Fundação Leão XIII, Rio de Janeiro, fev. 1947, art. 10.

${ }^{21}$ Gleide Guimarães, Entrevista concedida ao projeto História e Memória de Manguinhos desenvolvido pela Casa de Oswaldo Cruz/ Fiocruz, Acervo DAD/COC, 2004.
} 
aos funcionários da limpeza pública. Foram também criados, porém com características de construção permanente, os conjuntos Casa da Moeda, destinados a seus funcionários, ex-combatentes, famílias dos que retornaram da Segunda Guerra Mundial, e o Conjunto Tiradentes.

Na década de 1960, nos primeiros governos do Estado da Guanabara, tanto Carlos Lacerda (1960-1965)22 como Negrão de Lima (1965-1970) direcionaram políticas para as favelas com ações de remoção vinculadas a interesses sociopolíticos e econômicos. Negrão de Lima intensificou as remoções, por meio da atuação da Coordenação de Habitação de Interesse Social da Área Metropolitana do Grande Rio (CHISAM), e estabeleceu forte controle sobre as associações de moradores, pela Secretaria de Serviços Sociais.

Na década de 1970, o projeto originalmente idealizado por Jânio Quadros, em 1961, e retomado pela Superintendência de Urbanização e Saneamento (SURSAN) em 1965, no governo Carlos Lacerda, foi revisto por Chagas Freitas, o qual fundou o Projeto Rio e o Programa de Erradicação de Favelas (PROMORAR). As favelas não foram erradicadas, sendo que algumas passaram por processos de urbanização, principalmente aquelas localizadas em áreas de palafita.

A redemocratização do Brasil, ao final da década de 1970, incorporou algumas reivindicações populares e inseriu a elaboração de programas que propunham obras urbanísticas e incluíam a regularização fundiária, mantendo, no entanto, o deslocamento entre as duas questões, o que favoreceu, como analisa Rafael Gonçalves, a "superdensificação das favelas e a permanência da mesma precariedade jurídica". ${ }^{23}$ Contribuiu também a legislação que incluiu o usucapião e admitiu a construção de habitações sem legalização prévia, o que descartava as remoções em massa, sem apontar uma solução clara para a questão fundiária. A ocupação de terrenos sem legalização favoreceu o crescimento de um mercado de imóveis e de construções em favelas com documentação sem validade jurídica, porém com uma validação interna à favela.

O movimento de industrialização da área, verificado ao redor da década de 1950, inverteu-se a partir da última década do século XX com a desativação de várias indústrias e empresas impulsionada por fatores econômicos e, em especial neste espaço, pelos constantes conflitos entre os grupos organizados em torno do tráfico de drogas e da criminalidade, inclusive policial. ${ }^{24} \mathrm{O}$ deslocamento dessas instituições, ou a liberação de parte dos terrenos, foi em alguns casos negociado por grupos de moradores ou lideranças ou, mesmo, intermediado pelo Estado, como a Embratel e a ECT, o que possibilitou, neste caso, a construção de dois conjuntos habitacionais. Outras áreas, inclusive da própria Embratel, foram ocupadas sem negociação.

O governador Leonel Brizola, eleito em 1983 com grande apoio popular, incorporou reivindicações populares às políticas estatais e apresentou projetos de urbanização das favelas, o que estimulou os moradores a substituírem os barracos por

\footnotetext{
${ }^{22}$ Carlos Lacerda promoveu a destruição de 27 favelas e a transferência de 41.958 pessoas. Lícia do Prado Valladares, Passa-se uma casa: análise do Programa de remoção de favelas do rio de Janeiro, Rio de Janeiro, Zaar Editores, 1978. ${ }^{23}$ Rafael Soares Gonçalves, "A Política, o Direito e as favelas do Rio de Janeiro: um breve olhar histórico", Urbana Revista eletrônica do Centro Interdisciplinar de Estudos da Cidade, Universidade Estadual de Campinas, vol. 1, 2006. p. 10.

${ }^{24} \mathrm{O}$ processo recente de desocupação de áreas por indústrias e empresas foi fruto de uma análise formulada por Heitor Ney Mathias da Silva, As ruínas da cidade industrial: resistência e apropriação social do local, Dissertação (Mestrado em Planejamento Urbano e Regional), Universidade Federal do Rio de Janeiro, Rio de Janeiro, 2008.
} 
casas de alvenaria. Foram implantados programas como o "Cada família um lote", os quais, porém, permaneceram sem agregar políticas de legalização de propriedade. Habitações vendidas e alugadas em terrenos ocupados tornaram-se um importante comércio com mercado valorizado diante das novas construções.

Na década seguinte, na gestão de César Maia, implementou-se no município do Rio de Janeiro o Programa "Favela-Bairro" (1993), acatando uma das determinações da Constituição de 1988, e transformando as favelas em bairros. Este fato garantia a manutenção das moradias, com permanência, no entanto, da falta de instrumento legal de propriedade. Manguinhos não foi contemplada nesse programa 'curiosamente' por ser considerada uma área de extrema complexidade com bolsões de pobreza, alta densidade demográfica e tráfico de drogas e por necessitar de alternativas técnicas muito complexas e dispendiosas, devido às peculiaridades do solo, à ocupação em áreas não edificantes, à necessidade de drenagem do solo e à instalação de redes de captação de esgoto sanitário, como foi informado pelos técnicos da Prefeitura à época, Marcia Garrido, José Stelberto Soares e Maria Lúcia Petersen. ${ }^{25}$

\section{Programas como o "Cada família um lote" permaneceram sem agregar politicas de legalização de propriedade}

A transformação de Manguinhos em bairro, seguindo a legislação de 1988, passou, desta forma, ao largo da principal intervenção urbanística das favelas, observando-se obras pontuais que seguiam lógicas eleitoreiras e de interesses específicos, como narrado por vários moradores.

\section{Comunidades de Manguinhos: suas origens e algumas histórias}

Apesar da similaridade tipológica, as comunidades de Manguinhos apresentam singularidades geográficas e momentos diferenciados de formação que ajudaram a promover identidades próprias. Uma das características que as aproximam é o crescimento da densidade demográfica nos últimos 30 anos que se deve, principalmente, à ocupação de novos espaços, principalmente oriundos dos terrenos das empresas transferidas da localidade, às novas construções, à verticalização das moradias, à ampliação familiar, à transformação de moradias em ocupações multifamiliares e à ampliação do mercado interno de imóveis. Um traço importante para Manguinhos é o deslocamento interno pela mercantilização dos imóveis e pela fragilidade da locação e aquisição dos mesmos.

${ }^{25}$ Marcia Garrido, Entrevista, Rio de Janeiro, 24 abril de 2009. Projeto História e Memória de Manguinhos, Casa de Oswaldo Cruz/ Fiocruz (Acervo DAD/ COC); José Stelberto Soares, Entrevista, Rio de Janeiro, 22 de abril de 2009. Projeto História e Memória de Manguinhos, Casa de Oswaldo Cruz/ Fiocruz (Acervo DAD/ COC); Maria Lúcia Petersen, Entrevista, Rio de Janeiro, 2 de abril de 2009, Projeto História e Memória de Manguinhos, Casa de Oswaldo Cruz/Fiocruz (Acervo DAD/COC). 
Tabela 1. Comunidades do Complexo de Manguinhos por data de criação e/ou ocupação.

\begin{tabular}{lc} 
Comunidades & Origem ou reestruturação (ano) \\
\hline Parque Oswaldo Cruz/Morro do Amorim & 1901 \\
Comunidade Vila União & 1915 e 1955 \\
Parque Carlos Chagas/Varginha & 1941 \\
\hline Parque João Goulart & 1951 \\
Comunidade Vila Turismo & 1951 \\
Centro de Habitação Provisória no 2 (CHP2) & 1951 \\
Conjunto Habitacional Nélson Mandela & 1990 \\
Conjunto Habitacional Samora Machel & 1991 \\
Comunidade Mandela de Pedra & 1995 e 2010 \\
Comunidade Embratel/Samora II & 2001 \\
Comunidade Vitória de Manguinhos/ Conab/Cobal & 2002 \\
Comunidade/Condomínio CCPL & 2005 \\
Comunidade Embratel II/Condomínio Embratel & 2007 e 2010 \\
Condomínio DSUP & 2010
\end{tabular}

A área atualmente referenciada como Manguinhos não corresponde ao bairro traçado pela legislação de 1988, e sim aos Programas de Aceleração do Crescimento (PAC) e de Saúde da Família (PSF), o que nos levou a redimensionar nossa pesquisa, seguindo a listagem de comunidades na Tabela 1.

As denominações que sinalizam inclusive uma das diferenciações entre elas foram criadas, em geral, pelos próprios moradores, indicando a localização por vizinhança com outra comunidade ou assumindo o nome da empresa loteada, produzindo designações múltiplas que retratam a informalidade dos loteamentos.

O início da ocupação deu-se nas primeiras décadas do século XX, na única região de colina, no Parque Oswaldo Cruz, também denominado Morro do Amorim ou, atualmente Amorim, por meio do loteamento das fazendas produtoras de gêneros alimentícios que abasteciam a cidade, favorecido também pela instalação do IOC. ${ }^{26}$ Os primeiros moradores eram migrantes de origem portuguesa e de outras regiões do país ou da cidade, além de funcionários do IOC, com forte identificação com a origem de bairros dos subúrbios cariocas. A terminologia 'morro' para a área do Amorim, apesar de relacionada à colina, é contestada por alguns moradores, diante da caracterização de favela, como enfatiza Elza de Oliveira quando expressa que "eu não considero ali favela não. Eles dizem que é favela, mas não é favela, não". Também acrescenta, "é tudo calçado, casas lindas, muito bem construídas, muito bem acabadas por dentro".27

As décadas de 1940 e 1950 marcaram o início da profunda ocupação de Manguinhos atrelado a vários determinantes político-sociais, além da abertura de eixos viários (Avenidas Leopoldo Bulhões e Brasil, Rodovia Rio-Bahia) e aterramento das áreas marginais à Avenida Leopoldo Bulhões e aos rios que cortam a região. Poucas casas instaladas em uma área inóspita, úmida e sem serviços públicos, conforme narrado por vários moradores entrevistados,

\footnotetext{
${ }^{26}$ Benedito Tadeu Oliveira, Renato Gama-Rosa Costa, Alexandre Pessoa, Um Lugar para a Ciência. A formação do campus de Manguinhos, Rio de Janeiro, Fiocruz, 2003.

${ }^{27}$ Elza de Souza Oliveira, Entrevista concedida ao projeto História e Memória de Manguinhos desenvolvido pela Casa de Oswaldo Cruz/Fiocruz,Acervo DAD/COC, 12 de abril de 2004.
} 
como Nicolina Laia e seu marido João Felipe dos Santos, ${ }^{28}$ marcam esse período. De um lado da avenida instalou-se a comunidade de Varginha e do outro, na região originalmente reconhecida como Manguinhos, ${ }^{29}$ foram as comunidades de Parque João Goulart, Vila Turismo e do Centro de Habitação Provisória nº 2 (CHP2).

Varginha é a única comunidade de tal período que não se originou de conjuntos habitacionais. Foi criada por iniciativas individuais com casas de material provisório, transformadas posteriormente em alvenaria. O Parque João Goulart e o CHP2 têm suas procedências em conjuntos habitacionais construídos em madeira ou alvenaria, com aparência atual bastante diferenciada e múltipla. A Vila Turismo também apresenta alta diversidade interna e histórias diferentes. Um assentamento de cerca de 70 famílias oriundas da Ilha de Sapucaia ${ }^{30}$ marcou um trecho com casas de madeira em centro de terreno, que atualmente foram substituídas por alvenaria e quase totalmente modificadas e ampliadas, inclusive com crescimento vertical. Outros dois espaços no mesmo local retratam a luta de grupos para a ocupação do solo em diferentes momentos. Um desses, oriundos de outras favelas, como Catacumba, Praia do Pinto e Esqueleto, ocupou uma área pertencente à Marinha, utilizada como campo de futebol, com forte repressão policial, como detalhou em entrevista a moradora Nazaré de Jesus. ${ }^{31}$ Outro grupo de moradores se organizou para ocupação de uma região, que foi denominada Vila Democrática como retrato das lutas sociais da década de 1970, e atualmente se transformou em uma rua fechada com a denominação de Rua Projetada, em contraponto à informalidade de outros espaços.

Grandes problemas de infraestrutura marcaram a história das três comunidades vizinhas - CHP2, João Goulart e Vila Turismo - , tais como a proximidade com a adutora da Companhia Estadual de Águas e Esgotos (CEDAE), a rede e as torres de alta tensão da Companhia de Energia Elétrica LIGHT e os constantes incêndios e inundações. Atualmente, apresenta um perfil bastante diferenciado do inicial, com ampla ocupação em alvenaria que expõe os diferentes estratos sociais das comunidades, além da presença de grupos armados do tráfico de drogas e de milicianos que se instalaram a partir da década de 1980, com confronto constante entre os mesmos e a polícia.

A década de 1950 demarcou, ainda, a estruturação de outra comunidade, a Vila União, localizada na Avenida Suburbana (atualmente Dom Helder Câmara), formada por três conjuntos habitacionais - Casa da Moeda, Tiradentes e Excombatentes - em terreno de propriedade do Governo Federal (União), cercados por moradias populares. A denominação de Vila União surgiu com a ocupação da área do entorno dos prédios, ao longo da margem do Rio Jacaré e da linha do trem, apesar de já existir um pequeno grupo de casas constituído a partir de uma chácara arrendada à União desde 1915, inicialmente denominada Barracão. Essa região mostra claramente os diferentes estratos sociais das comunidades com os conjuntos dos prédios de origem delimitada pelo Estado

\footnotetext{
${ }^{28}$ Nicolina Laia, Entrevista concedida ao projeto História e Memória de Manguinhos desenvolvido pela Casa de Oswaldo Cruz/Fiocruz, Acervo DAD/COC, 26 de abril de 2004

${ }^{29}$ Apesar de o bairro ser denominado Manguinhos, alguns moradores mais antigos ainda identificam esta denominação apenas para esta área.

30Essas famílias foram transferidas para a construção da Universidade Federal do Rio de Janeiro.

${ }^{31}$ Nazaré Jesus, Entrevista, Rio de Janeiro, 20 de março de 2009, Projeto História e memórias de Manguinhos, Casa de Oswaldo Cruz/Fiocruz (Acervo DAD/COC).
} 
(Ex-Combatentes, Casa da Moeda e Tiradentes) e as casas e os barracos ocupados desordenadamente, o que provoca divergências e segregação, explicitada, inclusive, na denominação da comunidade conhecida como Vila União e Excombatentes. A legislação de 1988, que estabeleceu a delimitação dos bairros da cidade, ignorou esta possível distinção e formalizou este grupo como Vila União, vinculado ao Bairro de Benfica, o qual, porém, com a inclusão no PAC, passou a ser incorporado à Manguinhos.

Os movimentos populares de destaque na década de 1990 por reivindicação de políticas habitacionais para moradores das áreas de risco incluíram negociações com a Prefeitura e construção de dois conjuntos - Nelson Mandela (1990) e Samora Machel (1991) — na Avenida Leopoldo Bulhões entre o Rio Jacaré e o Canal do Cunha, próximos à Embratel e à ECT. A construção desses loteamentos foi um retrato da força das reivindicações populares, não somente para a concretização do projeto, como para o estabelecimento do tamanho das habitações ou para a escolha do nome dos conjuntos, como narrado por lideranças deste movimento, como Paulo César Moreira ${ }^{32}$ e Gleide Guimarães. ${ }^{33}$ Tais construções facilitaram a intensa ocupação das áreas próximas, numa conjuntura de densificação demográfica e crescimento dos grupos armados, responsáveis, inclusive, por parte das novas ocupações, que ocorreram em grupos organizados, ao contrário do que aconteceu em outras áreas de Maguinhos com movimentos individuais.

Foram criadas em trechos vizinhos pertencentes às empresas Embratel, ECT e Conab, sem intermediação do Estado, quatro comunidades - Mandela de Pedra (1995), Embratel/Samora II (2001), Vitória de Manguinhos/Conab/Cobal (2002) e Embratel II (2007) —, que, apesar de histórias bastante articuladas entre si, apresentam profundas distinções no que diz respeito ao processo de ocupação e ao perfil atual em 2012.

A comunidade Mandela de Pedra (1995), considerada a mais precária da região, fez uso de uma parte do terreno que estava sendo negociada pela Prefeitura com as empresas Embratel e ECT, para construir um novo conjunto habitacional, que não se concretizou diante da rápida ocupação e da mudança de condução política após as eleições municipais.

Tal movimento, segundo a moradora Gleide Guimarães, ${ }^{34}$ seguia a ideia "de invadir para ganhar casa", baseado no pressuposto de que as pessoas que ocupassem os terrenos seriam cadastradas pelo governo para reassentamento, mesmo que este se desse em outra comunidade. Uma parte de Mandela de Pedra foi incluída no PAC/Manguinhos (2010/2012), com obras de saneamento e urbanização e realocação de famílias residentes nas áreas de risco.

A comunidade Embratel (2001), também denominada Samora II, por estar em uma parte do terreno da empresa Embratel e contígua à comunidade Samora Machel, foi organizada, segundo alguns moradores, por lideranças do tráfico de drogas, que cadastraram os moradores interessados e coordenaram a ocupação. Esta deveria seguir um desenho com becos e vielas e um cronograma que viabilizasse

32 Paulo César Moreira, Entrevista concedida ao projeto História e Memória de Manguinhos desenvolvido pela Casa de Oswaldo Cruzl Fiocruz, Acervo DAD/COC, 2008.

${ }^{33 G}$ Gleide Guimarães, Entrevista concedida ao projeto História e Memória de Manguinhos desenvolvido pela Casa de Oswaldo Cruz/ Fiocruz, Acervo DAD/COC, 08 de março de 2004

${ }^{34}$ Ibidem. 
a ocupação rápida do terreno, o que de fato ocorreu, inclusive, com verticalização das casas, conforme alguns residentes que solicitaram anonimato relataram.

Vitória de Manguinhos/Conab ou Cobal foi uma comunidade constituída em 2002, como fruto da invasão dos galpões abandonados da antiga Conab, situados na Rua Leopoldo Bulhões na calçada oposta à sede da ECT, chefiada por moradores da Comunidade Mandela de Pedra. Uma liderança desta invasão, Julio César Soares Aragão, ${ }^{35}$ fundador da Associação de Moradores e Amigos de Vitória de Manguinhos, narrou o processo de ocupação da área estimulado por ele, diante do início do desmonte dos prédios por alguns moradores de Mandela de Pedra, propondo a divisão e instalação das famílias nos terrenos da empresa com aproveitamento da estrutura dos galpões. Ao longo de dez anos esta área foi densamente povoada, tendo alojado também um forte esquema de tráfico de drogas.

A última área, liderada também por moradores de Mandela de Pedra, constituiu Embratel II (2007) e deu continuidade à ocupação de outra parte do terreno e dos galpões da empresa Embratel, que já se encontrava desativada.

A partir do final de 2006, com a circulação de informações sobre a possibilidade de implantação do PAC-Manguinhos na região, houve ampliação do número de habitações, algumas apenas de fachada e de divisão interna das casas com a perspectiva, por parte de moradores e de lideranças locais, de garantir um maior número de moradias nos futuros conjuntos habitacionais a serem construídos na área.

Tal Programa, resultado de uma parceria entre os governos federal, estadual e municipal, alterou algumas áreas, com obras de saneamento, urbanização e construção de creches e reinstalou parte dos moradores, de algumas comunidades (Embratel/Samora II, Embratel II, ${ }^{36}$ Parque João Goulart, Conjunto Nelson Mandela, Mandela de Pedra e CCPL ${ }^{37}$ ) por meio de estratégias como compra assistida, indenização e aluguel social. Foram construídos três conjuntos habitacionais - D-SUP, Embratel e CCPL - com proposta de incorporação da ideia de condomínio residencial.

O Condomínio D-SUP ${ }^{38}$ foi construído em uma área ao lado da Vila União, onde se localizava o Depósito de Suprimentos do Exército do quartel de subsistência Pandiá Calógeras, composto por 721 moradias distribuídas em prédios de apartamentos. $\mathrm{O}$ antigo galpão do quartel, os armazéns e a portaria passaram a abrigar algumas das estruturas sociais como a Biblioteca Parque de Manguinhos, a Unidade de Pronto Atendimento (UPA), a Clínica de Saúde da Família, o Centro de Referência da Juventude (CRJ), a Casa da Mulher, o

\footnotetext{
35Julio César Soares Aragão, Entrevista concedida ao projeto História e Memória de Manguinhos desenvolvido pela Casa de Oswaldo Cruz/ Fiocruz, Acervo DAD/COC, 26 de novembro de 2003.

${ }^{36}$ A Equipe Técnica do Trabalho Social do Programa de Aceleração do Crescimento (PAC/Manguinhos) identifica a primeira parte do terreno da antiga Embratel como Samora II ou Terrenos (sendo inclusive incorporada na área de atuação da Associação de Moradores do Conjunto Samora Machel), e a segunda ocupada, apenas pelo nome de Embratel, que em alguns momentos chegou a ser denominada por algumas lideranças locais como Nova Era ou Nova Mandela.

${ }^{37}$ A Comunidade Cooperativa Central dos Produtores de Leite LTDA (CCPL) não compõe o bairro de Manguinhos, mas foi incluída no PAC Manguinhos, frente à proximidade espacial e às negociações estabelecidas.

${ }^{38} \mathrm{~A}$ denominação D-SUP referente ao quartel aparece como DSUP, D SUP ou DESUP, nos diferentes documentos oficiais. O PAC Manguinhos e as estruturas sociais da comunidade anotam D-SUP. O condomínio é dividido em dois grupos de prédios: D-SUP 1 (Blocos 1 a 5 com 568 apartamentos) e D-SUP 2 (Blocos 6 e 7 com 153 apartamentos).
} 
Centro de Apoio Jurídico, o Núcleo de Geração de Trabalho e Renda, a Escola Estadual Compositor Luis Carlos da Vila e o Centro Esportivo-Aquático.

O Condomínio Embratel foi implantado nos terrenos habitados pela comunidade Embratel II e pelos galpões da empresa, que foram totalmente demolidos, dando lugar a um conjunto de 480 unidades habitacionais e a uma creche. Esse processo foi liderado por Leonardo Januário da Silva e envolveu denúncias ${ }^{39}$ de interesses pessoais e de grupos na aquisição dos apartamentos, ainda não elucidadas.

O último condomínio ${ }^{40}$ a ser construído na área seria o CCPL, cuja remoção dos moradores para a criação de prédios somente terminou em 2012, como Candida Maria Privado ${ }^{41}$ contou, como liderança da negociação com os poderes públicos. Trata-se de uma comunidade criada, em 2005, por ocupação da Companhia Central dos Produtores de Leite LTDA (CCPL) em moldes semelhantes a outras comunidades de Manguinhos, nas quais indústrias foram ocupadas para moradia.

Se por um lado, a Associação de Moradores
configura-se como uma forma de "legalização"
da cidadania, por outro, significa o exercício de
autoridade das lideranças sobre a
própria comunidade

Em geral, no processo de organização das ocupações mais recentes, criava-se uma Associação de Moradores, que tinha, como uma de suas funções, legalizar as comunidades frente ao Estado, por meio do Cadastro Nacional de Pessoa Jurídica (CNPJ). Essa se constitui como uma forma de reconhecimento legal dos moradores frente ao Estado, possibilitando o acesso a alguns serviços públicos e a inserção nos programas de atendimento escolar e de saúde, já que tais habitações não se encontram legalizadas e, portanto, não estão incluídas no cadastro da cidade. Se por um lado, a Associação de Moradores configura-se como uma forma de "legalização" da cidadania, por outro, significa o exercício de autoridade das lideranças sobre a própria comunidade, algumas inclusive controladas pelo poder paralelo do tráfico de drogas ou das milícias. No momento, são essas organizações que negociam o reconhecimento dos direitos do cidadão morador da favela, pelas lideranças, muitas com vínculos empregatícios nas instâncias governamentais e nos gabinetes de políticos.

\footnotetext{
${ }^{39}$ Vera Araújo, Líder da favela do Mandela é preso por negociar apartamentos do PAC, O Globo, Rio de Janeiro, 21 de janeiro de 2012.

${ }^{40} \mathrm{O}$ condomínio em construção irá abrigar apenas uma parcela dos moradores então realocados da Comunidade CCPL; o restante, segundo informações do trabalho social, serão realocados em unidades habitacionais em outros bairros.

${ }^{4}$ Maria Candida Privado, Entrevista concedida ao projeto História e Memória de Manguinhos desenvolvido pela Casa de Oswaldo Cruz/Fiocruz, Acervo DAD/COC, O8 de agosto de 2011.
} 


\section{Conclusões}

A observação do conjunto das comunidades de Manguinhos permite perceber blocos de ocupação com períodos específicos atrelados a momentos e conjunturas sociopolíticas determinadas, produzidos por movimentos esparsos e individuais, mobilizações populares, ocupações por grupos e políticas públicas, os quais geraram agregação, consolidaram as comunidades e criaram laços de identidade e tensões.

A construção de novos conjuntos habitacionais, no início do século XXI, trouxe uma nova fase para a região, no que diz respeito aos aspectos estruturais e às relações sociais e de poder. As negociações para a conquista das casas, as indenizações para as áreas removidas, o aluguel social, o possível tráfico de influências, a ingerência dos traficantes de drogas e milicianos e as mudanças sociais e incertezas configuram-se como questões antigas acionadas por um novo contexto, no qual a Prefeitura apresenta novas definições para as favelas do Rio de Janeiro.

Para essas redefinições foram criados critérios a partir da categorização de bairro, o que levou a Prefeitura e o Instituto Pereira Passos a elaborarem um novo quadro para a cidade e a enumerarem 44 ex-favelas, que passariam a ser reconhecidas diferentemente, o que gerou importantes discussões e posicionamentos políticos diferenciados ${ }^{42}$ principalmente em torno dos conjuntos estruturais e simbólicos construídos historicamente sobre as categorias favela e bairro.

As mudanças nas comunidades ocupadas pós-década de 1990, com a construção de conjuntos emblematizados como condomínios, foram conduzidas oficialmente pela Equipe Técnica do Trabalho Social do PAC, que atua no processo de realocação das famílias para as novas unidades habitacionais. Cabe também ao Trabalho Social "formar" os novos moradores, por meio do que é chamado de "encontros de integração", em que procedimentos e orientações quanto à vida condominial são repassados, ignorando as várias questões relacionadas à identidade do morador com seu espaço. As casas próximas, as ruas estreitas, os vizinhos, os barulhos, os odores, os laços de amizade e a familiaridade foram substituídos por prédios com outras características, distintas das que formatavam as histórias das famílias envolvidas.

A atual conjuntura de Manguinhos, no que tange a essas mudanças, requer análise específica constituindo-se tema de nossa investigação em curso.

\footnotetext{
42"Moradores e vizinhos de ex-favelas discordam de critérios da Prefeitura", O Globo, Rio de Janeiro, 30 de maio de 2011, Rogério Daflor; Selma Schmidt, "O caminho para se chegar à cidade formal", O Globo, Rio de Janeiro, 5 de junho de 2011 .
} 
